\title{
An investigation on chemical/mineral compositions, ruminal microbial fermentation, and feeding value of some leaves as alternative forages for finishing goats during the dry
} season

\author{
Mohsen Kazemi* (i)
}

\begin{abstract}
Finding new fodder resources with moderate to high nutritional value that are cheaper and available is one of the most challenges in livestock industries. Hence, the nutritive value of some tree leaves (quince, pear, olive, mirabelle plum, greengage, sour cherry, and persimmon) was investigated by different laboratories and in vitro methods. Also, partial substitution of alfalfa and corn silage (50\%) with these leaves was investigated using forty-eight goats in a randomized complete block design in vivo. Highest total phenol and tannin contents were obtained in quince $(p<0.001)$. Greengage $(146.37 \mathrm{~g} / \mathrm{kg} \mathrm{DM})$ and persimmon $(136.96 \mathrm{~g} / \mathrm{kg} \mathrm{DM})$ exhibited the highest crude protein, respectively $(p<0.001)$. Calcium content $(19.82 \mathrm{~g} / \mathrm{kg} \mathrm{DM})$ was highest in persimmon leaves $(p<0.001)$. Greengage $(66.07 \mathrm{mmol} / \mathrm{L})$ and mirabelle plum $(65.58 \mathrm{mmol} / \mathrm{L})$ produced more total volatile fatty acids in the culture medium, respectively $(p<0.001)$. Potential gas production ranged from $39.65 \mathrm{~mL}$ for pear to $55.32 \mathrm{~mL}$ mirabelle plum. Sour cherry had the highest acid-base buffering capacity $\left(183.73 \mathrm{mEq} \times 10^{-3}, p<0.001\right)$. Highest dry matter intake (1087 g/ day) and crude protein digestibility $(70.80 \%)$ were observed in diets containing greengage $(p<0.001)$. Total antioxidant capacity of serum increased when olive, quince, and persimmon were considered in goats feeding $(p<0.001)$. Although all studied leaves can be fed in diets of goats without deleterious effects on performance, serum, and hematology parameters, in vivo and in vitro results indicated that greengage in terms of nutritive value was superior to other studied leaves.
\end{abstract}

Keywords: Feed, Goat, Leaves, Nutritional value, Growth performance

\section{Introduction}

Due to the growing population, the global demand for animal proteins is increasing. Also, the supply of animal feeds is one of the major costs associated with livestock industries. Therefore, searching for alternative feed resources that are palatable and low-cost, and can meet the nutritional requirements of small ruminants is one

\footnotetext{
*Correspondence: phd1388@gmail.com

Department of Animal Science, Faculty of Agriculture and Animal Science, University of Torbat-e Jam, Torbat-e Jam, Iran
}

of the major goals for livestock farming (Abegunde and Akinsoyinu 2011). Foliage leaves are major feed resources for small ruminant production in arid and semi-arid regions of Iran, especially in smallholder farms. Also, in these areas, the leaves of some trees are rich in nutrients and can be grazed in the fall season by small ruminants when they fall to the ground. It is reported that tree leaves contain moderate levels of nitrogen, minerals, and vitamins (Patra 2009). Also, it is reported that leaves of mulberry trees as a protein resource could be used in sheep diets containing ammoniated rice straw and rapeseed 
meal (Liu et al. 2001). The substitution of conventional ingredients by tree leaves will make diets cheaper rather than commercial feeds (Ondiek et al. 2000). Although foliage leaves have been extensively used in small ruminant feeding, their excessive consumption due to the secondary compounds (such as phenol and tannin) can be harmful to the small ruminants (Salem 2005; Salem et al. 2006). However, it is well known that moderate levels of tannins in the ration (3-4\% of DM tannins) can have beneficial effects on the availability of protein for ruminants (Min and Solaiman 2018). Quince is a plant belonging to Rosaceae whose medicinal characteristics as a result of phenolic compounds are reported extensively (Ashraf et al. 2016). Pear with a diverse range of phenolic compounds is one of the first broadly consumed fruits within the world and utilized as a traditional cure in Asia due to their antitussive, anti-inflammatory, and diuretic exercises (Jung et al. 2004; Cui et al. 2005; Fischer et al. 2007). Olive leaves as agricultural residues are reported to be rich in total phenol $(63.5 \mathrm{~g} / \mathrm{kg} \mathrm{DM})$ and lignin $(109 \mathrm{~g} /$ kg DM) contents (Abbeddou et al. 2011). The Mirabelle plum from the Rosaceae family is principally known for high dietary fiber, sorbitol, phenolic compounds (commonly as chlorogenic and neochlorogenic acids), potassium, and boron (Stacewicz-Sapuntzakis et al. 2001), organoleptic and nutritional characteristics (Ioannou et al. 2011). A suitable level of minerals is reported for two varieties of greengage cultivar (Rosaceae family) in Spain (Reig et al. 2018). Sour cherry with high polyphenol and flavonoid contents belongs to the Rosaceae family whose antioxidant capacity of leaves is proven (Nowak et al. 2016). Persimmon with potential antioxidant activity is a plant of the Ebenaceae family, whose leaves have different therapeutic effects on the cardiovascular system, blood pressure, myocardial apoptosis, immune system, etc. (Xie et al. 2015). Lack of general information on the nutritive value of alternative forage resources can lead to unbalanced diets, low livestock growth and animal protein production, and subsequently low income for animal husbandries. Hence, different laboratories, in vitro, and in vivo methods were designed for determining and comparing the nutritive value of some tree leaves (quince, pear, olive, mirabelle plum, greengage, sour cherry, and persimmon) available in Iran and other countries.

\section{Material and methods}

\section{Area collection and leaves samples}

Different orchards located in Kashmar city were randomly selected for leaf sampling [i.e., quince (Cydonia oblonga Mill.), pear (Pyrus communis L.), olive (Olea europaea L.), mirabelle plum (Prunus domestica L.), greengage (Prunus domestica L.), sour cherry (Prunus cerasus L.), and persimmon (Diospyros kaki L.)].
Kashmar $\left(35^{\circ} 14^{\prime} \mathrm{N}\right.$ and $58^{\circ} 27^{\prime} \mathrm{E}, 206 \mathrm{~mm}$ average rainfall, and an average temperature of $17.7^{\circ} \mathrm{C}$ ) with semi-arid weather is located in the north east of Iran, Khorasan Razavi province. The leaves were randomly picked by hand from different orchards when $\sim 40 \%$ of the leaves had fallen and $80 \%$ had turned yellow. For the in vitro trial, the leaves of 20 different trees were randomly collected, mixed and a $5 \mathrm{~kg}$ subsample was transferred to the laboratory for more analysis. The collected leaves from different orchards were left on the ground to be dried (with $90 \% \mathrm{DM}$ ) and then preserved in a roofed barn until the start of the in vivo experiment.

\section{Laboratory analysis}

The samples of fresh leaves were moved to an air-forced oven (Behdad Co., Iran) (method no. 930.15) for dry matter (DM) determination (AOAC 2005). The methods recommended by AOAC (2005) were used for the determination of ash (method no. 942.05), ether extract (EE, method no. 991.36), and crude protein (CP, Kjeldahl, $\mathrm{N} \times 6.25$, method no. 954.01) contents. The concentrations of acid detergent fiber (ADF), acid detergent lignin (ADL), and neutral detergent fiber (NDF) were determined by procedures of Ankom technology (2005,2006a; b) with reagents described by Van Soest et al. (1991). The concentrations of total phenolic, tannins, and non-tannin phenolic (NTP) were determined according to protocol of Makkar (2003b). The procedure of Jasaitis et al. (1987) was employed to determine the buffering capacity and $\mathrm{pH}$ of the samples. An atomic absorption spectrophotometer (SavantAA, GBC, Australia) was employed to determine mineral contents (calcium, phosphorus, potassium, sodium, magnesium, manganese, cobalt, iron, zinc, and copper). Phosphorus was determined by a UV-visible spectrophotometer (Photonix-Ar-2017, Iran) using the molybdovanadate method.

\section{In vitro rumen fermentation}

The method of Menke and Steingass (1988) was employed for the run of in vitro gas test. Rumen fluid was collected from three fistulated Sistani male goats, strained through four layers of cheesecloth, and kept in a warm water bath at $39^{\circ} \mathrm{C}$. The diet of animals was prepared based on NRC (2007) at the maintenance level (60:40 forage-to-concentrate ratio). About $200 \mathrm{mg}$ of each leaf sample ( $1 \mathrm{~mm}$ screen, Arthur H. Thomas, Philadelphia, PA, USA) was placed into a $100 \mathrm{~mL}$ glass syringe with four replicates. Rumen fluid and artificial saliva $(30 \mathrm{~mL})$ were mixed in a 1:2 ratio, added to each syringe, and incubated in a water bath at $39^{\circ} \mathrm{C}$ for $3,6,9,12,24,48,72$, and $96 \mathrm{~h}$. The respective gas production was recorded at the each of mentioned times. Four syringes without leaf samples 
in each run were also considered as blank. The gas test was replicated in two runs.

The $\mathrm{pH}$ of the culture medium was determined immediately with a pH meter (Hana, Model HI 2210-01, USA) following the filtration of each syringe content. After $24 \mathrm{~h}$ incubation, the content of each syringe was strained using a Buchner funnel equipped with a polyester cloth (45-micron pore size, Kazemi and Ghasemi Bezdi 2021). The strained content was moved into the pre-weighed crucible, washed with the neutral detergent solution, and dried in a forced-air oven at $60^{\circ} \mathrm{C}$ (Makkar 2010) for $48 \mathrm{~h}$. The method of Makkar (2010) was used for true DM and organic matter digestibility (TDMD and TOMD), and partitioning factor (PF) determination. The amount of $10 \mathrm{~mL}$ of the filtered solution was mixed with $10 \mathrm{~mL}$ of $0.2 \mathrm{~N} \mathrm{HCl}$ and stored in $\mathrm{a}-18^{\circ} \mathrm{C}$ freezer until ammonia nitrogen $\left(\mathrm{NH}_{3}-\mathrm{N}\right)$ analysis. The concentration of $\mathrm{NH}_{3}-\mathrm{N}$ was determined by the Kjeldahl method (Komolong et al. 2001). The protocol described by Getachew et al. (2004) was used for sampling of total volatile fatty acids (VFA). The analysis of VFA was done by gas chromatography equipped (YL6100 GC; Young Lin Instrument, Anyang, South Korea) with a $50 \mathrm{~m}$ silica-fused (0.32 mm ID) column (CP-Wax Chrompack Capillary Column, Varian, Palo Alto, CA, USA). Internal standard and carrier gas were crotonic acid (trans-2-butenoic acid) and helium, respectively. Initial and final oven temperatures were 55 and $195^{\circ} \mathrm{C}$, respectively. A temperature of $250{ }^{\circ} \mathrm{C}$ was set for the detector and injector.

\section{Treatments and animal experiment}

Forty-eight Sistani male goats $(19 \pm 1.5 \mathrm{~kg}, 7$-month-old) were allocated to eight treatment $(n=6$ per treatment). Treatments were (1) control (basal diet containing alfalfa and corn silage); (2) Quince (50\% alfalfa and 50\% corn silage were substituted with quince leaves); (3) Pear $(50 \%$ alfalfa and $50 \%$ corn silage were substituted with pear leaves); (4) Olive (50\% alfalfa and $50 \%$ corn silage were substituted with olive leaves); (5) Mirabelle Plum (50\% alfalfa and $50 \%$ corn silage were substituted with mirabelle plum); (6) Greengage (50\% of alfalfa and 50\% corn silage were substituted with greengage leaves); (7) Sour cherry $(50 \%$ of alfalfa and $50 \%$ corn silage were substituted with sour cherry leaves); (8) Persimmon (50\% of alfalfa and $50 \%$ corn silage were substituted with persimmon leaves). This project was conducted in a sheep husbandry farm in Kashmar, Khorasan Razavi, Iran. Before the experiment started, goats were dewormed with albendazole. Each animal was kept in a $2 \mathrm{~m} \times 2 \mathrm{~m}$ individual pen with free access to clean water. A 14-day adaptation was considered before the treatments are applied. Diets were formulated based on NRC instructions (2007) with a forage to concentrate ratio of 40:60 (DM basis). Feed was offered to animals twice a day at 07:00 and 19:00 h. After overnight fasting, goats were weighted before and every 30 days after the trial for monitor body weight change. The experiment lasted for 90 days. Feed intake and refusal were recorded throughout the trial. The animals were allowed to acclimatize to the fecal bags for 3 days. On the 83rd day of the experiment, a 7-day period was considered for the digestion trial. Total fecal was collected into the fecal bags. These bags were emptied and weighted two times a day. Sampling from total fecal, feed, and refusal was done for DM and chemical analysis. Blood samples were taken $3 \mathrm{~h}$ after morning feeding via jugular vein and the mean of two consecutive days ( 89 and 90) was considered for final statistical analysis. The collected blood samples were divided into two tubes, one containing ethylenediaminetetraacetic acid (EDTA) as an anticoagulant agent for hematology assessment and the other was anticoagulant free for biochemical assay. The concentration of hemoglobin $(\mathrm{Hb})$, white blood cells (WBC), red blood cells (RBC), packed cell volume (PCV), mean corpuscular hemoglobin $(\mathrm{MCH})$, mean corpuscular volume $(\mathrm{MCV})$, and mean corpuscular hemoglobin (MCHC) were determined using an automated hematology analyzer (CellTac $\alpha$, MEK-6450, Nihon Kohden, Japan). The malondialdehyde (MDA) concentration was determined as thiobarbituric acid-reactive substances according to Placer et al. (1966). The colorimetric antioxidant assay kit (Cayman Chemical Company, USA) was used for total antioxidant capacity (TAC) determination at the absorbance of $405 \mathrm{~nm}$ with a microplate reader. The blood serum including total protein (TP), albumin, creatinine, triglyceride, cholesterol, high-density lipoprotein cholesterol (HDL-C), low-density lipoprotein cholesterol (LDL-C), blood urea nitrogen (BUN), glucose, aspartate aminotransferase (AST), and alanine aminotransferase (ALT) were measured using an auto-analyzer (A15, Biosystem, Spain) after centrifugation (Eppendorf AG, Hamburg, Germany) at $3000 \times g$ for $10 \mathrm{~min}$.

\section{Calculations and statistical analysis}

The equations presented by Menke and Steingass (1988) were employed to determine net energy for lactation (NEl) and metabolism energy (ME). The data of gas production were analyzed using the following equation: $Y=b\left(1-e^{-c t}\right)$, where $Y=$ the volume of gas production at time $\mathrm{t}, b=$ the potential gas production after $96 \mathrm{~h}$ incubation $(\mathrm{mL} /$ per $200 \mathrm{mg} \mathrm{DM}), c=$ the fractional rate of gas production for $\mathrm{b}(\% / \mathrm{h})$, and $t=$ the incubation time $(\mathrm{h})$ (Ørskov and McDonald 1979).

The data related to in vitro and laboratory studies were analyzed in a completely randomized design using GLM procedure of SAS statistical package (SAS Institute Inc. 2002) with the following model: $Y_{i j}=\mu+T_{i}+e_{i j}$, where 
$\mathrm{Y}_{\mathrm{ij}}=$ the value of each observation, $\mu=$ overall mean, $\mathrm{T}_{\mathrm{i}}=$ treatment effect and $\mathrm{e}_{\mathrm{ij}}=$ experimental error.

The data of in vivo section were analyzed in a randomized complete block design using GLM procedure of SAS statistical package (SAS Institute Inc. 2002) with the following model: $Y_{i j}=\mu+T_{i}+B_{j}+e_{i j}$, where $Y_{i j}=$ the response variable, $\mu$ is the overall mean, $T_{i}=$ the treatment effect, $B_{j}=$ the block effect, and eij=the random error. Statistical differences between means of in vivo and in vitro data were determined using the Duncan test at $p \leq 0.05$.

\section{Results}

\section{Chemical and mineral contents}

The chemical contents of some leaves are presented in Table 1 . The tested leaves had different chemical content. Highest DM content (481.62 $\mathrm{g} / \mathrm{kg}$ fresh weight) was obtained in quince $(p<0.001)$. The concentration of NDF ranged from 324.73 for sour cherry to $484.80 \mathrm{~g} / \mathrm{kg} \mathrm{DM}$ for olive. The content of ADF also differed from 161.20 for greengage to $299.63 \mathrm{~g} / \mathrm{kg}$ DM for olive. Greengage (146.37) and persimmon (136.96 g/kg DM) exhibited the highest $\mathrm{CP}$ content, respectively $(p<0.001)$. Olive had the highest ADL (136.55 g/kg DM) and EE (39.67 g/ $\mathrm{kg} \mathrm{DM})$ $(p<0.001)$. The highest content of NFC was observed in pear and sour cherry, respectively $(p<0.001)$. The highest concentrations for total phenol $(91.49 \mathrm{~g} / \mathrm{kg} \mathrm{DM})$ and tannins $(85.76 \mathrm{~g} / \mathrm{kg} \mathrm{DM})$ were obtained in quince $(p<0.001)$. Olive had the lowest non-tannin phenol $(3.75 \mathrm{~g} / \mathrm{kg} \mathrm{DM}$, $p=0.001$ ) among tree leaves.
The mineral contents of some leaves are exhibited in Table 2. Exception cobalt, different mineral contents were observed among leaves $(p<0.001)$. Persimmon had the highest calcium (19.82 $\mathrm{g} / \mathrm{kg} \mathrm{DM}, p<0.001)$. The highest contents of phosphorus $(3.02 \mathrm{~g} / \mathrm{kg} \mathrm{DM})$, potassium $(19.41 \mathrm{~g} / \mathrm{kg} \mathrm{DM})$, sodium $(0.80 \mathrm{~g} / \mathrm{kg} \mathrm{DM})$, and zinc $(29.67 \mathrm{mg} / \mathrm{kg} \mathrm{DM})$ were obtained in mirabelle plum $(p<0.001)$. Quince had the highest concentrations of iron $(136.67 \mathrm{mg} / \mathrm{kg} \mathrm{DM})$ and copper $(11.49 \mathrm{mg} / \mathrm{kg} \mathrm{DM})$ $(p<0.001)$. The content of manganese $(135.03 \mathrm{mg} / \mathrm{kg}$ $\mathrm{DM})$ in pear was highest among leaves $(p<0.001)$. The concentration of magnesium differed from 3.73 for olive to $7.54 \mathrm{~g} / \mathrm{kg}$ DM for greengage.

\section{In vitro ruminal fermentation}

The $\mathrm{pH}, \mathrm{NH}_{3}-\mathrm{N}$, individual and total VFA of the culture medium following the incubation of some leaves are presented in Table 3. The highest $\mathrm{pH}$ of the culture medium was observed when sour cherry (6.74) and quince (6.71) were incubated, respectively $(p<0.001)$. The lowest $\mathrm{NH}_{3}-\mathrm{N}(15.67 \mathrm{mg} / \mathrm{dL})$ was obtained in olive $(p=0.02)$. Total VFA were highest in greengage $(66.07 \mathrm{mmol} / \mathrm{L})$ and mirabelle plum $(65.58 \mathrm{mmol} / \mathrm{L})$, respectively $(p<0.001)$. Greengage (23.03), mirabelle plum (21.87), and sour cherry $(20.83 \mathrm{~mol} / 100 \mathrm{~mol})$ exhibited the highest propionate, respectively $(p<0.01)$. Other individual VFA containing acetate, butyrate, valerate, and isovalerate were not different among tree leaves $(p>0.05)$.

The gas test parameters, ME, NEl, true nutrient digestibility, microbial mass yield (MMY), and PF obtained for some leaves are presented in Table 4. Different gas production parameters were observed among

Table 1 Chemical contents ( $/ \mathrm{kg} \mathrm{DM}$ ) of some leaves

\begin{tabular}{|c|c|c|c|c|c|c|c|c|c|}
\hline \multirow[t]{2}{*}{ Item } & \multicolumn{7}{|l|}{ Leaf } & \multirow[t]{2}{*}{ SEM } & \multirow[t]{2}{*}{$p$-value } \\
\hline & Quince & Pear & Olive & Mirabelle plum & Greengage & Sour cherry & Persimmon & & \\
\hline DM & $481.62^{a}$ & $461.11^{b c}$ & $471.33^{\mathrm{ab}}$ & $443.60^{c}$ & $401.18^{d}$ & $390.59^{d}$ & 353.00 & 3.78 & $<0.001$ \\
\hline NDF & $426.67^{b}$ & $340.00^{c}$ & $484.80^{\mathrm{a}}$ & $470.87^{\mathrm{a}}$ & $405.97^{b}$ & $324.73^{c}$ & $478.10^{a}$ & 7.28 & $<0.001$ \\
\hline ADF & $286.63^{\mathrm{a}}$ & $189.37^{b c}$ & $299.63^{a}$ & $162.30^{c}$ & $161.20^{c}$ & $219.90^{\mathrm{b}}$ & $208.10^{\mathrm{bc}}$ & 9.89 & $<0.001$ \\
\hline ADL & $115.64^{\mathrm{ab}}$ & $70.34^{c}$ & $136.55^{\mathrm{a}}$ & $74.22^{c}$ & $69.29^{c}$ & $95.12^{\mathrm{bc}}$ & $73.62^{c}$ & 6.06 & $<0.001$ \\
\hline $\mathrm{CP}$ & $116.50^{\mathrm{cd}}$ & $111.38^{\text {de }}$ & $100.49^{e}$ & $127.51^{\mathrm{bc}}$ & $146.37^{\mathrm{a}}$ & $126.63^{b c}$ & $136.96^{\mathrm{ab}}$ & 2.72 & $<0.001$ \\
\hline $\mathrm{EE}$ & $18.33^{e f}$ & $17.40^{f}$ & $39.67^{\mathrm{a}}$ & $24.00^{c d}$ & $22.00^{\text {de }}$ & $26.67^{c}$ & $33.67^{b}$ & 0.79 & $<0.001$ \\
\hline Ash & $73.20^{c}$ & $76.07^{c}$ & $73.50^{c}$ & $116.20^{\mathrm{a}}$ & $120.20^{\mathrm{a}}$ & $91.13^{b}$ & $96.73^{b}$ & 2.73 & $<0.001$ \\
\hline NFC & $365.30^{b}$ & $455.15^{a}$ & $301.54^{c}$ & $261.42^{d}$ & $305.47^{c}$ & $430.83^{\mathrm{a}}$ & $254.53^{d}$ & 6.52 & $<0.001$ \\
\hline $\mathrm{TP}$ & $91.49^{\mathrm{a}}$ & $64.34^{c}$ & $61.84^{\mathrm{cd}}$ & $62.73^{c}$ & $55.12^{\text {de }}$ & $53.22^{e}$ & $73.14^{b}$ & 2.20 & $<0.001$ \\
\hline $\mathrm{TT}$ & $85.76^{\mathrm{a}}$ & $56.38^{\mathrm{cd}}$ & $58.09^{c}$ & $54.58^{\mathrm{cd}}$ & $49.70^{d}$ & $48.68^{d}$ & $68.13^{b}$ & 2.20 & $<0.001$ \\
\hline NTP & $5.72^{b}$ & $7.97^{\mathrm{a}}$ & $3.75^{c}$ & $8.15^{\mathrm{a}}$ & $5.42^{\mathrm{b}}$ & $4.53^{b c}$ & $5.01^{\mathrm{bc}}$ & 0.41 & 0.001 \\
\hline
\end{tabular}

Means with different letters within the same row are significantly different according to $p$-value indicated. NFC was calculated by subtracting CP, NDF, fat, and ash contents from total DM (Sniffen et al. 1992)

$D M$ (g/kg fresh weight) dry matter, NDF neutral detergent fiber, $A D F$ acid detergent fiber, $A D L$ acid detergent lignin, $C P$ crude protein, $E E$ ether extract, $N F C$ non-fiber carbohydrates, TP total phenol, TT total tannin, NTP non-tannin phenol, SEM standard error of the mean 
Table 2 Mineral contents of some leaves

\begin{tabular}{|c|c|c|c|c|c|c|c|c|c|}
\hline \multirow[t]{2}{*}{ Item } & \multicolumn{7}{|l|}{ Leaf } & \multirow[t]{2}{*}{ SEM } & \multirow[t]{2}{*}{$p$-value } \\
\hline & Quince & Pear & Olive & Mirabelle plum & Greengage & Sour cherry & Persimmon & & \\
\hline $\mathrm{Ca}$ & $11.18^{d}$ & $15.49^{b c}$ & $17.43^{b}$ & $14.48^{c}$ & $14.59^{c}$ & $14.47^{c}$ & $19.82^{\mathrm{a}}$ & 0.47 & $<0.001$ \\
\hline$P$ & $0.11^{\mathrm{e}}$ & $1.65^{c}$ & $1.19^{d}$ & $3.02^{\mathrm{a}}$ & $2.66^{a}$ & $2.13^{b}$ & $1.21^{\mathrm{d}}$ & 0.09 & $<0.001$ \\
\hline K & $9.20^{d}$ & $5.84^{e}$ & $7.33^{\text {de }}$ & $19.41^{\mathrm{a}}$ & $16.50^{b}$ & $12.45^{c}$ & $18.37^{\mathrm{ab}}$ & 0.51 & $<0.001$ \\
\hline $\mathrm{Na}$ & $0.51^{c}$ & $0.38^{d}$ & $0.51^{c}$ & $0.80^{\mathrm{a}}$ & $0.66^{b}$ & $0.52^{c}$ & $0.62^{b c}$ & 0.02 & $<0.001$ \\
\hline $\mathrm{Mg}$ & $6.55^{\mathrm{ab}}$ & $4.09^{b c}$ & $3.73^{c}$ & $3.96^{b c}$ & $7.54^{\mathrm{a}}$ & $6.52^{\mathrm{ab}}$ & $7.51^{\mathrm{a}}$ & 0.55 & $<0.001$ \\
\hline $\mathrm{Mn}$ & $48.10^{\text {de }}$ & $135.03^{\mathrm{a}}$ & $49.23^{\text {de }}$ & $57.43^{d}$ & $109.13^{b}$ & $39.53^{e}$ & $75.64^{c}$ & 2.11 & $<0.001$ \\
\hline Co & 2.43 & 2.87 & 2.50 & 2.80 & 2.40 & 2.43 & 2.63 & 0.27 & 0.79 \\
\hline $\mathrm{Fe}$ & $136.67^{\mathrm{a}}$ & $95.12^{c}$ & $97.57^{c}$ & $106.33^{b c}$ & $108.08^{b c}$ & $120.20^{\mathrm{ab}}$ & $109.58^{\mathrm{bc}}$ & 4.46 & $<0.001$ \\
\hline $\mathrm{Zn}$ & $26.83^{\mathrm{ab}}$ & $27.63^{a b}$ & $14.53^{c}$ & $29.67^{a}$ & $22.07^{\mathrm{abc}}$ & $20.00^{b c}$ & $18.43^{c}$ & 1.63 & $<0.001$ \\
\hline $\mathrm{Cu}$ & $11.49^{\mathrm{a}}$ & $8.83^{b}$ & $3.24^{d}$ & $5.33^{c}$ & $4.83^{c}$ & $2.92^{d}$ & $3.52^{\mathrm{d}}$ & 0.16 & $<0.001$ \\
\hline
\end{tabular}

Means with different letters within the same row are significantly different according to $p$-value indicated

Ca calcium (g/kg DM), P phosphorus (g/kg DM), K potassium ( $/ \mathrm{kg} D M)$, Na sodium (g/kg DM), Mg magnesium (g/kg DM), Mn manganese (mg/kg DM), Co cobalt (mg/ $\mathrm{kg} \mathrm{DM})$, Fe iron (mg/kg DM), Zn zinc (mg/kg DM), Cu copper ( $\mathrm{mg} / \mathrm{kg} \mathrm{DM),} \mathrm{SEM} \mathrm{standard} \mathrm{error} \mathrm{of} \mathrm{the} \mathrm{mean}$

Table 3 The $\mathrm{pH}, \mathrm{NH}_{3}-\mathrm{N}$, individual and total volatile fatty acids of the culture medium following the incubation of some leaves

\begin{tabular}{|c|c|c|c|c|c|c|c|c|c|}
\hline \multirow[t]{2}{*}{ Item } & \multicolumn{7}{|l|}{ Leaf } & \multirow[t]{2}{*}{ SEM } & \multirow[t]{2}{*}{$p$-value } \\
\hline & Quince & Pear & Olive & Mirabelle plum & Greengage & Sour cherry & Persimmon & & \\
\hline $\mathrm{pH}$ & $6.71^{\mathrm{ab}}$ & $6.65^{b c}$ & $6.67^{b}$ & $6.58^{\mathrm{cd}}$ & $6.56^{\mathrm{d}}$ & $6.74^{\mathrm{a}}$ & $6.59^{c d}$ & 0.01 & $<0.001$ \\
\hline $\mathrm{NH}_{3}-\mathrm{N}(\mathrm{mg} / \mathrm{dL})$ & $16.03^{\mathrm{ab}}$ & $16.08^{\mathrm{ab}}$ & $15.67^{b}$ & $16.33^{\mathrm{ab}}$ & $17.06^{\mathrm{a}}$ & $16.46^{a b}$ & $16.79^{\mathrm{ab}}$ & 0.25 & 0.02 \\
\hline Total VFA (mmol/L) & $61.08^{c}$ & $59.75^{c}$ & $60.19^{c}$ & $65.58^{\mathrm{ab}}$ & $66.07^{a}$ & $63.60^{b}$ & $61.43^{c}$ & 0.44 & $<0.001$ \\
\hline $\mathrm{C} 2(\mathrm{~mol} / 100 \mathrm{~mol})$ & 62.00 & 61.83 & 62.67 & 62.50 & 62.00 & 63.17 & 62.17 & 0.49 & 0.53 \\
\hline C3 (mol/100 mol) & $19.83^{b c}$ & $19.33^{c}$ & $20.77^{a b c}$ & $21.87^{\mathrm{ab}}$ & $23.03^{a}$ & $20.83^{a b c}$ & $20.07^{b c}$ & 0.51 & $<0.01$ \\
\hline C4 (mol/100 mol) & 13.67 & 13.53 & 13.00 & 13.07 & 12.87 & 13.00 & 13.90 & 0.44 & 0.57 \\
\hline C5 $(\mathrm{mol} / 100 \mathrm{~mol})$ & 1.28 & 1.47 & 1.38 & 1.39 & 1.25 & 1.30 & 1.50 & 0.08 & 0.29 \\
\hline Iso-C5 (mol/100 mol) & 0.42 & 0.47 & 0.41 & 0.48 & 0.41 & 0.44 & 0.51 & 0.04 & 0.56 \\
\hline
\end{tabular}

Means with different letters within the same row are significantly different according to $p$-value indicated

$\mathrm{NH}_{3}-\mathrm{N}$ ammonia nitrogen, VFA volatile fatty acids, $\mathrm{C} 2$ acetate, $\mathrm{C} 3$ propionate, $\mathrm{C} 4$ butyrate, $\mathrm{C} 5$ valerate, Iso- $\mathrm{C} 5$ isovalerate, SEM standard error of the mean

tree leaves. The highest amount of $24 \mathrm{~h}$ gas production was observed in greengage (48.30) and mirabelle plum $(44.83 \mathrm{~mL})$, respectively $(p<0.001)$. The lowest potential gas production was related to pear leaves $(39.65 \mathrm{~mL}$, $p<0.001)$. Persimmon (0.054), quince (0.055), and olive $(0.057 \% / \mathrm{h})$ had the lowest fractional rate of gas production compared to other leaves, respectively $(p<0.001)$. Greengage had the highest content of ME $(9.73 \mathrm{MJ} / \mathrm{kg}$ $\mathrm{DM})$ and NEl $(5.81 \mathrm{MJ} / \mathrm{kg} \mathrm{DM})(p<0.001)$. The content of TDMD ranged from 644.91 for pear to $824.56 \mathrm{~g} /$ $\mathrm{kg}$ DM for greengage $(p<0.001)$. Greengage $(831.50)$, mirabelle plum (820.67), and sour cherry $(801.17 \mathrm{~g} / \mathrm{kg}$ DM) had the highest TOMD, respectively $(p<0.001)$. The microbial mass yield was different from 37.33 for pear to $63.27 \mathrm{mg}$ for greengage, respectively $(p<0.001)$. The lowest PF was obtained in pear (3.02), persimmon (3.29), and olive (3.33), respectively $(p<0.001)$.

\section{Buffering capacity parameters}

The $\mathrm{pH}$, titratable acidity, acid-buffering capacity, titratable alkalinity, base-buffering capacity, and acid-base buffering capacity $\left(\mathrm{mEq} \times 10^{-3}\right)$ of some leaves are shown in Table 5. The value of $\mathrm{pH}$ (5.26) for mirabelle plum was lowest among tree leaves $(p<0.001)$. Sour cherry had the highest titratable acidity $\left(258.75 \mathrm{mEq} \times 10^{-3}\right)$ and acid-base buffering capacity $\left(183.73 \mathrm{mEq} \times 10^{-3}\right)(p<0.001)$. Also, sour cherry $(113.13)$ and mirabelle plum $\left(108.17 \mathrm{mEq} \times 10^{-3}\right)$ exhibited the highest acid buffering capacity, respectively $(p<0.001)$. The highest amounts of titratable alkalinity $\left(271.25 \mathrm{mEq} \times 10^{-3}\right)$ and base-buffering capacity $\left(84.70 \mathrm{mEq} \times 10^{-3}\right)$ were observed in quince $(p<0.001)$. 
Table 4 The gas test parameters, ME, NEl, true nutrient digestibility, MMY, and PF measured for some leaves

\begin{tabular}{|c|c|c|c|c|c|c|c|c|c|}
\hline \multirow[t]{2}{*}{ Item } & \multicolumn{7}{|l|}{ Leaf } & \multirow[t]{2}{*}{ SEM } & \multirow[t]{2}{*}{$p$-value } \\
\hline & Quince & Pear & Olive & Mirabelle plum & Greengage & Sour cherry & Persimmon & & \\
\hline gas $12 \mathrm{~h}(\mathrm{~mL})$ & $27.06^{b}$ & $27.20^{b}$ & $26.10^{\mathrm{bc}}$ & $35.23^{\mathrm{a}}$ & $36.16^{a}$ & $32.16^{\mathrm{a}}$ & $21.93^{c}$ & 1.03 & $<0.001$ \\
\hline gas $24 \mathrm{~h}(\mathrm{~mL})$ & $36.70^{b}$ & $33.60^{b}$ & $34.63^{b}$ & $44.83^{a}$ & $48.30^{a}$ & $37.13^{b}$ & $36.73^{b}$ & 0.86 & $<0.001$ \\
\hline gas $48 \mathrm{~h}(\mathrm{~mL})$ & $47.50^{\mathrm{bc}}$ & $37.90^{d}$ & $47.30^{\mathrm{bc}}$ & $52.77^{a}$ & $51.30^{\mathrm{ab}}$ & $44.83^{c}$ & $44.93^{c}$ & 0.96 & $<0.001$ \\
\hline gas $72 \mathrm{~h}(\mathrm{~mL})$ & $51.60^{\mathrm{ab}}$ & $40.80^{c}$ & $51.13^{b}$ & $55.67^{\mathrm{a}}$ & $52.53^{\mathrm{ab}}$ & $48.50^{b}$ & $50.47^{b}$ & 0.93 & $<0.001$ \\
\hline gas $96 \mathrm{~h}(\mathrm{~mL})$ & $53.03^{\mathrm{abc}}$ & $42.03^{d}$ & $52.50^{\mathrm{abc}}$ & $57.20^{\mathrm{a}}$ & $55.20^{\mathrm{ab}}$ & $49.80^{c}$ & $51.36^{b c}$ & 1.07 & $<0.001$ \\
\hline$b(\mathrm{~mL})$ & $52.36^{\mathrm{ab}}$ & $39.65^{d}$ & $51.48^{\mathrm{abc}}$ & $55.32^{\mathrm{a}}$ & $52.18^{\mathrm{ab}}$ & $47.29^{c}$ & $50.69^{b c}$ & 0.94 & $<0.001$ \\
\hline c (\%/h) & $0.055^{d}$ & $0.104^{b}$ & $0.057^{d}$ & $0.081^{c}$ & $0.125^{a}$ & $0.088^{c}$ & $0.054^{d}$ & 0.003 & $<0.001$ \\
\hline ME (MJ/kg DM) & $7.94^{c}$ & $7.48^{d}$ & $7.92^{c}$ & $9.17^{b}$ & $9.73^{\mathrm{a}}$ & $8.16^{c}$ & $8.29^{c}$ & 0.12 & $<0.001$ \\
\hline NEI (MJ/kg DM) & $4.56^{c}$ & $4.24^{d}$ & $4.56^{c}$ & $5.42^{b}$ & $5.81^{\mathrm{a}}$ & $4.70^{c}$ & $4.78^{c}$ & 0.09 & $<0.001$ \\
\hline TDMD (g/kg DM) & $679.18^{c}$ & $644.91^{c}$ & $666.65^{c}$ & $808.25^{\mathrm{ab}}$ & $824.56^{\mathrm{a}}$ & $786.77^{b}$ & $657.03^{c}$ & 7.37 & $<0.001$ \\
\hline TOMD (g/kg DM) & $690.33^{b}$ & $660.73^{b}$ & $689.67^{b}$ & $820.67^{\mathrm{a}}$ & $831.50^{\mathrm{a}}$ & $801.17^{a}$ & $684.83^{b}$ & 8.27 & $<0.001$ \\
\hline $\mathrm{MMY}(\mathrm{mg})$ & $38.50^{c}$ & $37.33^{c}$ & $38.10^{c}$ & $61.80^{\mathrm{a}}$ & $63.27^{a}$ & $49.17^{b}$ & $38.33^{c}$ & 1.49 & $<0.001$ \\
\hline PF & $3.53 b^{c}$ & $3.02^{d}$ & $3.33^{\mathrm{cd}}$ & $3.87^{\mathrm{ab}}$ & $4.15^{\mathrm{a}}$ & $3.91^{\mathrm{ab}}$ & $3.29^{\mathrm{cd}}$ & 0.08 & $<0.001$ \\
\hline
\end{tabular}

Means with different letters within the same row are significantly different according to $p$-value indicated

gas $12,24,48,72$, and $96 \mathrm{~h}$ cumulative gas production after $12,24,48,72$, and $96 \mathrm{~h}$ incubation; $b$ potential gas production; $c$ fractional rate of gas production ME metabolism energy, NEI net energy for lactation, TDMD true dry matter digestibility, TOMD true organic matter digestibility, MMY microbial mass yield, $P F$ partitioning factor (mg TOMD/mL $24 \mathrm{~h}$ gas production), SEM standard error of the mean

Table 5 The $\mathrm{pH}$, titratable acidity, acid-buffering capacity, titratable alkalinity, base-buffering capacity, and acid-base buffering capacity $\left(\mathrm{mEq} \times 10^{-3}\right)$ of some leaves

\begin{tabular}{|c|c|c|c|c|c|c|c|c|c|}
\hline \multirow[t]{2}{*}{ Item } & \multicolumn{7}{|l|}{ Leaf } & \multirow[t]{2}{*}{ SEM } & \multirow[t]{2}{*}{$p$-value } \\
\hline & Quince & Pear & Olive & Mirabelle plum & Greengage & Sour cherry & Persimmon & & \\
\hline $\mathrm{pH}$ & $6.03^{b}$ & $5.92^{c}$ & $5.87^{c}$ & $5.26^{f}$ & $5.71^{d}$ & $6.29^{\mathrm{a}}$ & $5.57^{e}$ & 0.02 & $<0.001$ \\
\hline Titratable acidity & $172.75^{b}$ & $164.75^{b}$ & $148.00^{c}$ & $136.75^{d}$ & $152.25^{c}$ & $258.75^{a}$ & $127.25^{d}$ & 2.25 & $<0.001$ \\
\hline Acid-buffering capacity & $85.13^{\mathrm{bcd}}$ & $85.69^{b c}$ & $79.31^{d}$ & $108.17^{\mathrm{a}}$ & $88.77^{b}$ & $113.13^{\mathrm{a}}$ & $81.05^{\mathrm{cd}}$ & 1.30 & $<0.001$ \\
\hline Titratable alkalinity & $271.25^{\mathrm{a}}$ & $228.50^{\mathrm{cd}}$ & $215.50^{\text {de }}$ & $241.75^{b c}$ & $247.50^{b}$ & $204.75^{\mathrm{e}}$ & $231.25^{\mathrm{bcd}}$ & 4.11 & $<0.001$ \\
\hline Base-buffering capacity & $84.70^{a}$ & $68.36^{b c}$ & $63.76^{\mathrm{cd}}$ & $60.48^{d}$ & $67.99^{\mathrm{bc}}$ & $70.60^{b}$ & $63.48^{\mathrm{cd}}$ & 1.17 & $<0.001$ \\
\hline Acid-base buffering capacity & $169.83^{b}$ & $154.05^{\mathrm{cd}}$ & $143.07^{e}$ & $168.65^{\mathrm{b}}$ & $156.77^{c}$ & $183.73^{\mathrm{a}}$ & $144.54^{\mathrm{de}}$ & 2.24 & $<0.001$ \\
\hline
\end{tabular}

Means with different letters within the same row are significantly different according to $p$-value indicated

SEM standard error of the mean

\section{Animal experiment \\ Performance and nutrient digestibility}

Ingredients and chemical composition of diets containing different leaves are shown in Table 6. The diets were relatively considered as isonitrogenous and isoenergetic. The effects of diets containing different leaves on nutrient digestibility and goats' performance are presented in Table 7. The highest dry matter intake (DMI, $1087 \mathrm{~g} /$ day) was related to diets containing greengage leaves $(p<0.001)$. Initial body weight $(\mathrm{BW})$ was unchanged at the start of experiment $(p>0.05)$, but final $\mathrm{BW}(p=0.001)$ and average daily gain (ADG, $p=0.05)$ were highest for diets containing greengage and mirabelle plum, respectively. Different nutrient digestibility was observed among treatments $(p<0.001)$. Greengage had the highest nutrient digestibility (exception EE) compared to the control group $(p<0.001)$.

\section{Blood plasma and hematology parameters}

The effects of diets containing different leaves on plasma and hematology parameters of goats are presented in Table 8. There was a significant difference for some plasma parameters among animals fed diets containing different leaves, but hematology parameters were unchanged. Goats fed on diets containing persimmon and quince exhibited the lowest triglyceride $(p=0.02)$, cholesterol $(p<0.001)$ and LDL-C $(p<0.001)$ and highest HDL-C $(p<0.001)$ compared to the control group. Rather than control group, greengage had the highest 
Table 6 Ingredients and chemical composition of diets containing different leaves

\begin{tabular}{|c|c|c|c|c|c|c|c|c|}
\hline \multirow[t]{2}{*}{ Item } & \multicolumn{8}{|c|}{ Treatment } \\
\hline & Control & Quince & Pear & Olive & Mirabelle plum & Greengage & Sour cherry & Persimmon \\
\hline \multicolumn{9}{|l|}{ Ingredients (\% of DM) } \\
\hline Alfalfa hay & 27 & 13.5 & 13.5 & 13.5 & 13.5 & 13.5 & 13.5 & 13.5 \\
\hline Corn silage & 13 & 6.5 & 6.5 & 6.5 & 6.5 & 6.5 & 6.5 & 6.5 \\
\hline Tree leaf & 0 & 20 & 20 & 20 & 20 & 20 & 20 & 20 \\
\hline Barley grain & 18 & 18 & 18 & 18 & 18 & 18 & 18 & 18 \\
\hline Corn grain & 18 & 18 & 18 & 18 & 18 & 18 & 18 & 18 \\
\hline Canola meal & 9.5 & 9.5 & 9.5 & 9.5 & 9.5 & 9.5 & 9.5 & 9.5 \\
\hline Wheat bran & 9.5 & 9.5 & 9.5 & 9.5 & 9.5 & 9.5 & 9.5 & 9.5 \\
\hline$V_{\text {Vitamine-mineral }}^{\mathrm{a}}$ & 2 & 2 & 2 & 2 & 2 & 2 & 2 & 2 \\
\hline Magnesium oxide & 1 & 1 & 1 & 1 & 1 & 1 & 1 & 1 \\
\hline Dicalcium phosphate & 1 & 1 & 1 & 1 & 1 & 1 & 1 & 1 \\
\hline Salt & 1 & 1 & 1 & 1 & 1 & 1 & 1 & 1 \\
\hline \multicolumn{9}{|l|}{ Chemical composition } \\
\hline DM (\% of fresh weight) & 67.32 & 76.95 & 76.95 & 76.95 & 76.95 & 76.95 & 76.95 & 76.95 \\
\hline CP (\% of DM) & 14.59 & 14.44 & 14.34 & 14.32 & 14.66 & 14.94 & 14.64 & 14.85 \\
\hline NDF (\% of DM) & 35.95 & 32.76 & 31.03 & 33.93 & 33.65 & 32.35 & 30.72 & 33.79 \\
\hline NFC (\% of DM) & 39.5 & 42.7 & 44.4 & 41.3 & 41.5 & 41.6 & 44 & 40.6 \\
\hline Ash (\% of DM) & 10.4 & 10.2 & 10.26 & 10.21 & 10.21 & 11.14 & 10.56 & 10.67 \\
\hline EE (\% of DM) & 2.67 & 2.66 & 2.64 & 3.09 & 2.77 & 2.73 & 2.83 & 2.97 \\
\hline ME (Mcal/kg DM) & 2.28 & 2.30 & 2.31 & 2.27 & 2.28 & 2.27 & 2.30 & 2.27 \\
\hline TP (\% of DM) & 0 & 1.83 & 1.29 & 1.24 & 1.26 & 1.10 & 1.06 & 1.46 \\
\hline TT (\% of DM) & 0 & 1.72 & 1.13 & 1.16 & 1.09 & 0.99 & 0.97 & 1.36 \\
\hline NTP (\% of DM) & 0 & 0.11 & 0.16 & 0.08 & 0.16 & 0.11 & 0.09 & 0.10 \\
\hline
\end{tabular}

Control basal diet containing alfalfa hay and corn silage, DM dry matter, $C P$ crude protein, NDF neutral detergent fiber, $N F C$ non-fiber carbohydrates, $E E$ ether extract, ME metabolism energy, TP total phenol, $T T$ total tannin, NTP non-tannin phenol

${ }^{a}$ Per kg of premix contained $100 \mathrm{mg}$ vitamin $\mathrm{E}, 10 \mathrm{mg}$ vitamin B1, $20 \mathrm{mg}$ vitamin B2, 400,000 IU vitamin A, 100,000 IU vitamin D, 3\% calcium, $1.2 \%$ phosphorus, 4\% sodium, $1.1 \%$ magnesium, $1000 \mathrm{mg}$ copper, $60 \mathrm{mg}$ iodine, $2000 \mathrm{mg}$ manganese, $2000 \mathrm{mg}$ zinc, $3000 \mathrm{mg}$ iron, $60 \mathrm{mg}$ cobalt

Table 7 The effects of diets containing different leaves on nutrient digestibility and growth performance of goats

\begin{tabular}{|c|c|c|c|c|c|c|c|c|c|c|}
\hline \multirow[t]{2}{*}{ Item } & \multicolumn{4}{|c|}{ Treatment } & \multirow[b]{2}{*}{ Mirabelle plum } & \multirow[b]{2}{*}{ Greengage } & \multirow[b]{2}{*}{ Sour cherry } & \multirow[b]{2}{*}{ Persimmon } & \multirow[t]{2}{*}{ SEM } & \multirow[t]{2}{*}{$p$-value } \\
\hline & Control & Quince & Pear & Olive & & & & & & \\
\hline DMI (g/day) & $979^{d}$ & $977^{d}$ & $973^{d}$ & $971^{d}$ & $1045^{b}$ & $1087^{a}$ & $1003^{c}$ & $0.973^{d}$ & 0.008 & $<0.001$ \\
\hline Initial BW (kg) & 19.14 & 19.10 & 19.21 & 19.21 & 19.38 & 19.19 & 19.06 & 19.09 & 0.69 & 0.97 \\
\hline Final BW (kg) & $28.42^{b c}$ & $28.70^{b c}$ & $27.21^{c}$ & $28.06^{c}$ & $29.69^{\mathrm{ab}}$ & $30.55^{\mathrm{a}}$ & $28.75^{b c}$ & $28.37^{b c}$ & 0.48 & 0.001 \\
\hline ADG (kg/day) & $0.114^{b c}$ & $0.120^{\mathrm{abc}}$ & $0.100^{c}$ & $0.111^{b c}$ & $0.129^{\mathrm{ab}}$ & $0.142^{\mathrm{a}}$ & $0.121^{\mathrm{abc}}$ & $0.116^{\mathrm{abc}}$ & 0.009 & 0.05 \\
\hline \multicolumn{11}{|c|}{ Nutrient digestibility (\%) } \\
\hline DM & $64.33^{b c}$ & $64.11^{\mathrm{cd}}$ & $63.72^{\mathrm{cd}}$ & $63.39^{d}$ & $65.04^{\mathrm{ab}}$ & $65.42^{\mathrm{a}}$ & $65.06^{\mathrm{ab}}$ & $64.40^{\mathrm{bc}}$ & 0.28 & $<0.001$ \\
\hline NDF & $40.90^{\mathrm{bc}}$ & $39.00^{d}$ & $41.30^{\mathrm{abc}}$ & $39.14^{d}$ & $42.16^{\mathrm{ab}}$ & $42.57^{\mathrm{a}}$ & $42.02^{\mathrm{abc}}$ & $40.48^{\mathrm{cd}}$ & 0.52 & $<0.001$ \\
\hline $\mathrm{CP}$ & $67.51^{b c}$ & $67.48^{b c}$ & $66.36^{\mathrm{cd}}$ & $65.70^{d}$ & $68.93^{b}$ & $70.80^{a}$ & $68.61^{b}$ & $67.36^{b c}$ & 0.53 & $<0.001$ \\
\hline OM & $67.16^{\mathrm{cd}}$ & $67.10^{\mathrm{cd}}$ & $66.06^{d}$ & $66.11^{d}$ & $68.86^{\mathrm{ab}}$ & $70.12^{a}$ & $68.39^{b c}$ & $66.94^{\mathrm{cd}}$ & 0.47 & $<0.001$ \\
\hline $\mathrm{EE}$ & $50.42^{\mathrm{fg}}$ & $49.91^{\mathrm{g}}$ & $52.90^{\mathrm{cd}}$ & $55.46^{\mathrm{a}}$ & $52.08^{\mathrm{de}}$ & $51.43^{\mathrm{ef}}$ & $53.86^{b c}$ & $54.88^{\mathrm{ab}}$ & 0.49 & $<0.001$ \\
\hline
\end{tabular}

Means with different letters within the same row are significantly different according to $p$-value indicated

Control basal diet containing alfalfa hay and corn silage, $D M I$ dry matter intake, $B W$ body weight, $A D G$ average daily gain, $D M$ dry matter, NDF neutral detergent fiber, $C P$ crude protein, $O M$ organic matter, EE ether extract, SEM standard error of the mean 
Table 8 The effects of diets containing different leaves on plasma and hematology parameters of goats

\begin{tabular}{|c|c|c|c|c|c|c|c|c|c|c|}
\hline \multirow[t]{2}{*}{ Item } & \multicolumn{4}{|l|}{ Treatment } & \multirow[b]{2}{*}{ Mirabelle Plum } & \multirow[b]{2}{*}{ Greengage } & \multirow[b]{2}{*}{ Sour cherry } & \multirow[b]{2}{*}{ Persimmon } & \multirow[t]{2}{*}{ SEM } & \multirow[t]{2}{*}{$p$-value } \\
\hline & Control & Quince & Pear & Olive & & & & & & \\
\hline \multicolumn{11}{|l|}{ Plasma parameters } \\
\hline Total protein (g/dL) & 6.85 & 6.87 & 6.90 & 6.98 & 7.00 & 7.09 & 6.96 & 6.90 & 0.08 & 0.50 \\
\hline Albumin (g/dL) & 3.56 & 3.53 & 3.61 & 3.47 & 3.65 & 3.71 & 3.61 & 3.61 & 0.12 & 0.92 \\
\hline Creatinine (mg/dL) & 0.92 & 0.93 & 0.94 & 1.00 & 0.89 & 0.92 & 1.00 & 0.93 & 0.04 & 0.41 \\
\hline Triglyceride (mg/dL) & $36.38^{\mathrm{a}}$ & $34.53^{b}$ & $35.79^{a b}$ & $35.98^{\mathrm{ab}}$ & $36.77^{\mathrm{a}}$ & $36.54^{\mathrm{a}}$ & $36.35^{\mathrm{a}}$ & $34.41^{b}$ & 0.53 & 0.02 \\
\hline Cholesterol (mg/dL) & $67.91^{\mathrm{a}}$ & $64.82^{b}$ & $67.70^{a}$ & $67.16^{\mathrm{a}}$ & $67.71^{\mathrm{a}}$ & $68.43^{\mathrm{a}}$ & $67.48^{\mathrm{a}}$ & $64.04^{b}$ & 0.67 & $<0.001$ \\
\hline $\mathrm{HDL}-\mathrm{C}(\mathrm{mg} / \mathrm{dL})$ & $43.07^{b}$ & $45.98^{\mathrm{a}}$ & $43.88^{b}$ & $43.72^{b}$ & $43.90^{b}$ & $43.32^{b}$ & $44.40^{b}$ & $46.45^{\mathrm{a}}$ & 0.44 & $<0.001$ \\
\hline LDL-C (mg/dL) & $18.75^{\mathrm{a}}$ & $15.37^{\mathrm{b}}$ & $18.75^{\mathrm{a}}$ & $18.58^{\mathrm{a}}$ & $18.46^{\mathrm{a}}$ & $18.66^{\mathrm{a}}$ & $18.03^{\mathrm{a}}$ & $16.12^{b}$ & 0.40 & $<0.001$ \\
\hline BUN (mg/dL) & $15.95^{b}$ & $15.77^{b}$ & $15.71^{b}$ & $15.89^{b}$ & $16.07^{\mathrm{ab}}$ & $16.96^{\mathrm{a}}$ & $16.33^{\mathrm{ab}}$ & $15.59^{b}$ & 0.30 & 0.05 \\
\hline Glucose (g/dL) & $63.51^{\mathrm{a}}$ & $62.68^{\mathrm{a}}$ & $62.22^{\mathrm{a}}$ & $59.70^{b}$ & $64.09^{a}$ & $64.10^{\mathrm{a}}$ & $64.11^{\mathrm{a}}$ & $62.78^{a}$ & 0.41 & $<0.001$ \\
\hline $\mathrm{AST}(\mathrm{U} / \mathrm{L})$ & $48.54^{\mathrm{a}}$ & $46.89^{b}$ & $49.09^{a}$ & $49.40^{a}$ & $49.10^{a}$ & $49.10^{\mathrm{a}}$ & $48.83^{a}$ & $48.82^{a}$ & 0.55 & 0.05 \\
\hline $\operatorname{ALT}(U / L)$ & $17.07^{\mathrm{a}}$ & $15.64^{b}$ & $16.86^{\mathrm{a}}$ & $16.97^{\mathrm{a}}$ & $17.00^{\mathrm{a}}$ & $16.84^{\mathrm{a}}$ & $16.91^{\mathrm{a}}$ & $16.77^{\mathrm{a}}$ & 0.30 & 0.05 \\
\hline TAC (mmol/L) & $0.91^{c}$ & $1.13^{\mathrm{a}}$ & $0.90^{c}$ & $1.16^{\mathrm{a}}$ & $0.88^{c}$ & $0.89^{c}$ & $1.02^{b}$ & $1.12^{\mathrm{a}}$ & 0.03 & $<0.001$ \\
\hline $\mathrm{MDA}(\mathrm{nmol} / \mathrm{mL})$ & $2.73^{\mathrm{a}}$ & $2.32^{c}$ & $2.84^{\mathrm{a}}$ & $2.33^{c}$ & $2.84^{\mathrm{a}}$ & $2.84^{\mathrm{a}}$ & $2.50^{\mathrm{b}}$ & $2.29^{c}$ & 0.06 & $<0.001$ \\
\hline \multicolumn{11}{|l|}{ Hematology } \\
\hline WBC (Cell/ $\mu \mathrm{L})$ & $10,383.3$ & $10,770.3$ & $10,833.7$ & $10,580.3$ & $10,651.2$ & $10,741.0$ & $10,816.7$ & $10,832.3$ & 206.45 & 0.77 \\
\hline $\mathrm{RBC}\left(\times 10^{6} / \mu \mathrm{L}\right)$ & 15.53 & 15.05 & 15.07 & 15.03 & 15.56 & 15.40 & 15.69 & 15.66 & 0.29 & 0.51 \\
\hline MCV (fL) & 17.95 & 17.34 & 17.61 & 17.37 & 17.94 & 17.32 & 18.25 & 18.04 & 0.34 & 0.36 \\
\hline $\mathrm{MCH}(\mathrm{pg})$ & 6.12 & 6.08 & 6.14 & 6.12 & 6.13 & 6.07 & 6.20 & 6.17 & 0.11 & 0.98 \\
\hline $\mathrm{MCHC}(\mathrm{g} / \mathrm{dL})$ & 33.84 & 33.51 & 33.40 & 33.08 & 33.36 & 33.29 & 33.89 & 33.58 & 0.42 & 0.88 \\
\hline PCV (\%) & 27.37 & 27.25 & 27.26 & 27.29 & 28.45 & 28.15 & 28.54 & 28.57 & 0.49 & 0.17 \\
\hline Hemoglobin (g/dL) & 9.42 & 9.37 & 9.59 & 9.54 & 9.53 & 9.38 & 9.86 & 9.67 & 0.19 & 0.64 \\
\hline
\end{tabular}

Means with different letters within the same row are significantly different according to $p$-value indicated

Control basal diet containing alfalfa hay and corn silage, $H D L-C$ high-density lipoprotein cholesterol, $L D L$ - $C$ low-density lipoprotein cholesterol, $B U N$ blood urea nitrogen, $A S T$ aspartate aminotransferase, $A L T$ alanine aminotransferase, $T A C$ total antioxidant capacity, MDA malondialdehyde, WBC white blood cell, $R B C$ red blood cell, $M C V$ mean corpuscular volume, $M C H$ mean corpuscular hemoglobin, $M C H C$ mean corpuscular hemoglobin concentration, $P C V$ packed cell volume, $S E M$ standard error of the mean

$\operatorname{BUN}(p=0.05)$ and the lowest glucose concentration was observed in olive $(p<0.001)$. The concentrations of AST and ALT in quince were significantly decreased compared to the control group $(p=0.05)$. Olive, persimmon, and quince had the highest TAC and lowest MDA rather than other treatments $(p<0.001)$.

\section{Discussion}

\section{Chemical and mineral contents}

In line with the present study, different chemical composition was reported for some tree leaves (Prosopis cineraria, Acacia nilotica, and Albezia lebbek) (Bhatta et al. 2005). Moderate to high levels of CP in the studied leaves confirm their high nutritive value. It is reported that tree leaves contain high levels of $\mathrm{CP}$ and they are valuable for ruminants fed low-quality fodders, especially during the dry season when it is not possible to provide highquality forages (Salem et al. 2007). Topps (1992) reported that tree fodders are richer in CP, minerals, and digestible nutrients compared to grasses. In line with the present study, phenolic and tannin compounds have been reported for some tree leaves containing Acacia cyanophylla Lindl. (Ben Salem et al. 2005), Prosopis cineraria, Acacia nilotica, and Albezia lebbek (Bhatta et al. 2005). Tannins are a group of phenolic compounds that are naturally present in plants and their normal consumption can be beneficial to livestock (Dawson et al. 1999). The effects of these compounds are different but high consumption is often not recommended due to the binding of dietary carbohydrates and proteins and subsequently decrease in carbohydrates and protein digestibility (Martens et al. 2013). In the present study, a diverse range of tannins (48.68-85.76 g/kg DM) was observed among tree leaves. Although the inclusion of diets with phenolic compounds because of anti-inflammatory and antimicrobial activities along with antioxidant capacity can have beneficial effects on animal performance (Ignat et al. 2011), the suitable levels of phenolic compounds (53.22-91.49 g/kg DM) was observed among the studied leaves. A lower concentration of NTP (3.7-8.1 g/kg DM) for the studied leaves was observed than those reported for other tree leaves (10-57 g/kg DM) including Sesbania 
grandiflora, Melia dubia, Dillenia spp., Artocarpus heterophyllus, Commiphora caudata, Moringa oleifera, Leucaena leucocephala, and Acacia auriculiformis (Giridhar et al. 2018).

Determining the mineral composition of studied leaves can be useful in preparing a balanced diet for small ruminants. Also, animal feed is one of the major sources of minerals and utilization of agro-industrial byproducts may also affect the mineral status of livestock (Ribeiro et al. 2019). In the present study, concentration of calcium reported for all leaves was higher than those $(1.4-7.0 \mathrm{~g} / \mathrm{Kg} \mathrm{DM})$ reported for fodders (Freer et al. 2007). The contents of phosphorus (exception quince), potassium, magnesium, and sodium (exception pear, quince, olive, persimmon, and sour cherry) of studied leaves were respectively within or above the recommended dietary levels of $0.9-3,5,0.9-1.2$, and $0.7-1 \mathrm{~g} /$ $\mathrm{kg}$ DM for sheep (Freer et al. 2007). The mineral requirements of goats for copper, cobalt, manganese, and zinc are reported about $8-10,0.1,40-50$, and $50 \mathrm{mg} / \mathrm{Kg} \mathrm{DM}$ of diet, respectively (Meschy 2000). In this regard, pear (8.83) and quince (11.49 $\mathrm{mg} / \mathrm{kg} \mathrm{DM})$ leaves can easily meet the copper requirements of goats. Also, the concentrations of cobalt $(2.40-2.87 \mathrm{mg} / \mathrm{kg} \mathrm{DM})$ and manganese $(39.53-135.03 \mathrm{mg} / \mathrm{kg} \mathrm{DM})$ in the studied leaves are adequate in goat feeding, but they are deficient in zinc $(14.53-29.67 \mathrm{mg} / \mathrm{kg} \mathrm{DM})$. The iron content of all leaves was above the recommended dietary levels $(30-50 \mathrm{mg} / \mathrm{kg}$ DM) for sheep (Moniello et al. 2005).

\section{In vitro ruminal fermentation}

In the present study, similar to report of Getachew et al. (2004), a different molar proportions of VFA in the culture medium was observed. A decrease in $\mathrm{pH}$ value of the culture medium following the inclusion of greengage could be attributed to higher VFA yield compared to other leaves (Dijkstra et al. 2012). As Kazemi (2019) reported a positive correlation between $\mathrm{CP}$ and ammonia nitrogen of culture medium, a lower $\mathrm{NH}_{3}-\mathrm{N}$ in olive leaves can be related to its more CP.

The higher $24 \mathrm{~h}$ gas production in greengage and mirabelle plum can be attributed to higher total VFA produced in the culture medium as Kazemi and Valizadeh (2019) stated that a strong positive correlation has been observed between total VFA and gas production. Close to the present results, Shakeri et al. (2017) reported that the volume of gas produced after $96 \mathrm{~h}$ incubation for two varieties of olive leaves was 49.40 and $49 \mathrm{~mL} / 200 \mathrm{mg} \mathrm{DM}$, respectively. Differences in gas production among the leaves of the present study can be attributed to various chemical compositions (e.g. proportion, and nature of fiber) (Rubanza et al. 2003) along with different tannin content that may negatively affect the activity of rumen microorganisms (Goel and Makkar 2012). Despite greater content of tannin in quince leaves rather than other leaves, lowered potential gas production in pear leaves confirmed different effects of tannin nature besides its concentration (Makkar 2003a). In contrast, quince leaves (high level of tannin) resulted in a lower fractional rate of gas production (cgas). It is reported that tannins can reduce the rate of digestion to a greater extent than the potential extent of digestion (Makkar et al. 1995). In this regard, TDMD of leaves with lower tannin concentration (sour cherry, greengage, and mirabelle plum) was higher than leaves (quince and persimmon) containing higher tannin. In contrast with the present findings, some tropical tannin-containing leaves such as Syzygium cumini, Azadirachta indica, Ficus religiosa, and Acacia nilotica exhibited greater OM degradability and they improved microbial biomass yield ( $\mathrm{Pal}$ et al. 2015). The higher PF in greengage leaves indicated higher efficiency of microbial protein synthesis compared to other leaves. As PF is considered as an index of distribution of TOMD between fermentation gases and microbial biomass, and increased PF means less gas and more microbial biomass (Pawar et al. 2014), therefore higher PF in greengage leaves might be useful in reducing environmental pollution.

The buffering capacity of some protein sources and leguminous fodder has been reported to be greater than $85 \mathrm{mEq} \times 10^{-3}$ (Montañez-Valdez et al. 2013), which is consistent with the present study. The greatest acid-base buffering capacity in sour cherry leaves $\left(183.73 \mathrm{mEq} \times 10^{-3}\right)$ represented high control of it in maintaining the $\mathrm{pH}$ balance. Also, the highest acid buffering capacity was obtained in sour cherry leaves $\left(113.13 \mathrm{mEq} \times 10^{-3}\right)$, indicating that more acid is needed to change the $\mathrm{pH}$ of the water-soluble sample. It is reported that initial $\mathrm{pH}$ and titratable acidity are two major factor affecting on ruminal $\mathrm{pH}$. In the present study, the highest titratable acidity was obtained for sour cherry $\left(258.75 \mathrm{mEq} \times 10^{-3}\right)$, indicating high resistance to acidification. Given the value of $\mathrm{pH}$ and buffering capacity of the diets, it would be possible to predict the need for buffers to control and maintain rumen $\mathrm{pH}$ (Bujňák et al. 2011). All leaves had near-neutral $\mathrm{pH}$ and therefore their consumption may not lead to changes in rumen $\mathrm{pH}$. Also, the amount and compound of minerals in crude ash have a particular buffering effect on the plant's initial $\mathrm{pH}$ (Lević et al. 2005). Due to the different ash content of the studied leaves (73.20-120.20 g/kg DM), their buffering capacity was also different.

\section{Goat experiments}

This is the first experiment to evaluate some tree leaves in vivo. So, we had to compare the present results with other tree leaves containing tannin or phenolic contents. 
Feeding of all studied tree leaves to goats had no negative effect on DMI compared to the control group which may be due to better palatability (Raghuvansi et al. 2007). Although diets of present study were relatively isonitrogenous and isoenergetic, final BW and ADG increased in goats fed the greengage diet compared to the control group. This improvement could be related to an increase in DMI and nutrient digestibility (Table 7), and an increase in propionate concentration of culture medium following the incubation of greengage (Table 3). In line with the present results, goats fed on Paraserianthes falcataria, Moringa oleifera, and Calliandra calothyrsus leaves exhibited higher growth performance, nutrient digestibility, and feed efficiency when were compared to those fed on grass hay (Okoruwa and Ikhimioya 2020). The positive and negative effects of tannins have been reported by Makkar (2003a). It is reported that the great concentration of tannins in leaves can have deleterious effects on nutrient digestibility and nitrogen retention (Kamalak 2006). The use of some browse leaves is restricted because of their great tannin contents (Silanikove et al. 2001). Barry et al. (1986) reported that less than $4 \%$ of tannin in the diet can be beneficial for ruminants. In this regard, the concentration of tannins in the diets of the present study ranged from 0 to $1.72 \%$ DM. So, no deleterious effect of these amounts of tannins on the performance of tree leaves-fed goats was not observed.

The concentration of blood metabolites is an indicator for assessing the content of nutrients in the diet, and they will affect the physiological conditions of animals (Pambu-Gollah et al. 2000). Differences in some blood metabolites among the treatments were probably due to different DMI, nutrient digestibility, and ruminal fermentation parameters. The lower triglyceride, cholesterol, LDL-C, and higher HDL-C in goats fed on diets containing quince and persimmon leaves can be attributed to the lipid-lowering properties of quince (Umar et al. 2015) and persimmon (Zhang et al. 2016) as a result of high total flavonoids contents. A higher BUN concentration was observed in diet containing greengage compared to the control group. This increase in BUN can be related to increasing in CP digestibility and DMI. The concentration of BUN may be useful as an index of protein status among animals, and could help to prepare the nitrogenbalanced diets or identify problems with a feeding program (Kohn et al. 2005). In line with the present results, a linear decline in plasma glucose of kids was observed when alfalfa hay was substituted with olive leaves at levels of 7.5 and $15 \%$ of diet (Jabalbarezi Hukerdi et al. 2019). Previous studies demonstrated that olive (leaf or mill waste) extracts, or its main phenolic compound (oleuropein) has anti-diabetic effects (Liu et al. 2014; Guex et al. 2019). A decrease in serum AST and ALT of goats fed a diet containing quince leaves compared to the control group is in line with Adiban et al. (2019) who demonstrated quince had a preventive effect against diethylnitrosamine-induced liver cancer by decreasing serum biomarkers (ALT and AST) responsible for liver health. An increased TAC and a declined MDA in diets containing olive, persimmon, and quince leaves can be related to their antioxidant effects (Umar et al. 2015; Xie et al. 2015; Jabalbarezi Hukerdi et al. 2019). Indeed MDA is an output of the oxidation of unsaturated fatty acid induced by free radicals which its concentration could indirectly reflect the rate of body fat oxidation (Liu and $\mathrm{Ng}$ 2000). In this study, lack of significant effects on the hematological parameters of goats indicates there were no negative effects on animal health.

The data presented (laboratory, in vivo and in vitro) here confirm that all tree leaves have nutritional potential and some of dietary forage can be substituted with these leaves in the dry season, especially when availability of conventional forages are scarce. In terms of DMI, final BW, ADG, and nutrient digestibility (DM, OM, $\mathrm{NDF}$, and $\mathrm{CP}$ ), greengage leaves are preferred than other species. Quince and persimmon leaves had advantages in blood lipids lowering. The amounts of serum TAC and MDA improved when adding olive, persimmon, and quince leaves to goat's diets. Generally, each of the studied leaves had the advantages in goats feeding. However, more research and longer studies should be conducted to validate the positive and negative effects of supplementing these leaves in finishing goats and to determine the moderate feeding rates in dairy goats or other animals.

\section{Abbreviations \\ DM: Dry matter; CP: Crude protein; ADF: Acid detergent fiber; NDF: Neutral detergent fiber; ADL: Acid detergent lignin; EE: Ether extract; NTP: Non-tannin phenolic; EDTA: Ethylenediaminetetraacetic acid; DMI: Dry matter intake; OM: Organic matter; BW: Body weight; TAC: Total antioxidant capacity; ADG: Average daily gain; MDA: Malondialdehyde; RBC: Red blood cells; WBC: White blood cells; VFA: Volatile fatty acids; AST: Aspartate aminotransferase; ALT: Alanine aminotransferase; HDL-C: High-density lipoprotein cholesterol; LDL-C: Low-density lipoprotein cholesterol; TP: Total protein; Hb: Hemoglobin; MCV: Mean corpuscular volume; MCH: Mean corpuscular hemoglobin; MCHC: Mean corpuscular hemoglobin concentration; PCV: Packed cell volume; NEl: Net energy for lactation; ME: Metabolism energy; TDMD: True dry matter digest- ibility; TOMD: True organic matter digestibility; MMY: Microbial mass yield.}

\section{Acknowledgements}

This work was supported technically by the University of Torbat-e Jam. The assistant of Mr. Mehrdad Movahed Nasab, Mr. Meysam Ilnet, Mr. Hadi Nezamdoost, Mis Akram Vafadar, Mr. Ali Zahedi, and Mr. Morteza Ghasemi for carrying out this project are greatly acknowledged.

\section{Authors' contributions}

This project was conducted and written by MK. The author read and approved the final manuscript.

Funding

This study was funded by University of Torbat-e Jam. 
Availability of data and materials

Not applicable.

\section{Declarations}

\section{Ethics approval and consent to participate}

The Animal Ethics Committee at the University of Torbat-e Jam approved all the animal protocols used in the present experiment.

\section{Consent for publication}

Not applicable.

\section{Competing interests}

The author declares that there was no conflict of interest associated with this manuscript.

Received: 1 April 2021 Accepted: 18 May 2021

Published online: 27 May 2021

\section{References}

Abbeddou S, Rihawi S, Hess HD, Iñiguez L, Mayer AC, Kreuzer M (2011) Nutritional composition of lentil straw, vetch hay, olive leaves, and saltbush leaves and their digestibility as measured in fat-tailed sheep. Small Rum Res 96:126-135. https://doi.org/10.1016/j.smallrumres.2010.11.017

Abegunde TO, Akinsoyinu AO (2011) Replacement effects of Panicum maximum with Ficus polita on performance of West African dwarf goats. J Anim Physiol Anim Nutr 95:192-197. https://doi.org/10.1111/j.1439-0396. 2010.01040.x

Adiban H, Shirazi FH, Gholami S, Kamalinejad M, Hosseini SH, Noubarani M, Eskandari MR (2019) Chemopreventive effect of quince (Cydonia oblonga Mill.) fruit extract on hepatocellular carcinoma induced by diethylnitrosamine in rats. Int Pharm Acta 2:2-2. https://doi.org/10.22037/ipa.v2i1. 23003

AOAC (2005) Official Methods of Analysis. 18rd ed. AOAC International. Gaithersburg, USA

Ankom Technology (2005) Method for determining acid detergent lignin in Beakers. https://www.ankom.com/sites/default/files/document-files/ Method_8_Lignin_in_beakers_0.pdf. Accessed 8 Jan 2021

Ankom Technology (2006a) Acid detergent fiber in feeds-filter bag technique. https://www.ankom.com/sites/default/files/document-files/ Method_5_ADF_A200.pdf. Accessed 8 Jan 2021

Ankom Technology (2006b) Neutral detergent fiber in feeds-filter bag technique. https://www.ankom.com/sites/default/files/document-files/ Method_6_NDF_A200.pdf. Accessed 8 Jan 2021

Ashraf MU, Muhammad G, Hussain MA, Bukhari SN (2016) Cydonia oblonga M., a medicinal plant rich in phytonutrients for pharmaceuticals. Fron Pharmacol 7:1-20. https://doi.org/10.3389/fphar.2016.00163

Barry TN, Manley TR, Duncan SJ (1986) The role of condensed tannin in the nutritional value of Lotus pedunculatus for sheep. 4. Sites of carbohydrate and protein digestion as influenced by dietary reactive tannin concentration. Br J Nutr 55:123-137. https://doi.org/10.1079/BJN19850106

Bhatta R, Vaithiyanathan S, Singh NP, Shinde AK, Verma DL (2005) Effect of feeding tree leaves as supplements on the nutrient digestion and rumen fermentation pattern in sheep grazing on semi-arid range of India-I. Small Rum Res 60:273-280. https://doi.org/10.1016/j.smallrumres.2005.01.009

Bujňák L, Maskal'ová I, Vladimir V (2011) Determination of buffering capacity of selected fermented feedstuffs and the effect of dietary acid-base status on ruminal fluid pH. Acta Vet Brno 80:269-273. https://doi.org/10.2754/ avb201180030269

Cui T, Nakamura K, Ma L, Li JZ, Kayahara H (2005) Analyses of arbutin and chlorogenic acid, the major phenolic constituents in oriental pear. J Agric Food Chem 53:3882-3887. https://doi.org/10.1021/jf047878k

Dawson JM, Buttery PJ, Jenkins D, Wood CD, Gill M (1999) Effects of dietary quebracho tannin on nutrient utilisation and tissue metabolism in sheep and rats. J Sci Food Agric 79:1423-1430. https://doi.org/10.1002/(SICI) 1097-0010(199908)79:11\%3c1423:*AID-JSFA383\%3e3.0.CO:2-8

Dijkstra J, Ellis JL, Kebreab E, Strathe AB, López S, France J, Bannink A (2012) Ruminal $\mathrm{pH}$ regulation and nutritional consequences of low $\mathrm{pH}$. Anim
Feed Sci Technol 172:22-33. https://doi.org/10.1016/j.anifeedsci.2011.12. 005

Fischer TC, Gosch C, Pfeiffer J, Halbwirth H, Halle C, Stich K, Forkmann G (2007) Flavonoid genes of pear (Pyrus communis). Trees 21:521-529. https://doi. org/10.1007/s00468-007-0145-z

Freer M, Dove H, Nolan JV (2007) Nutrient requirements of domesticated ruminants. CSIRO Publishing, Australia

Getachew G, Robinson PH, DePeter EJ, Taylor SJ (2004) Relationships between chemical composition, dry matter degradation and in vitro gas production of several ruminant feeds. Anim Feed Sci Technol 111:57-71. https:// doi.org/10.1016/S0377-8401(03)00217-7

Giridhar KS, Prabhu TM, Singh KC, Nagabhushan V, Thirumalesh T, Rajeshwari YB, Umashankar BC (2018) Nutritional potentialities of some tree leaves based on polyphenols and rumen in vitro gas production. Vet World 11:1479-1485 https://doi.org/10.14202/vetworld.2018.1479-1485

Goel G, Makkar HP (2012) Methane mitigation from ruminants using tannins and saponins. Trop Anim Health Prod 44:729-739. https://doi.org/10. 1007/s11250-011-9966-2

Guex CG, Reginato FZ, de Jesus PR, Brondani JC, Lopes GHH, de Freitas BL (2019) Antidiabetic effects of Olea europaea L. leaves in diabetic rats induced by high-fat diet and low-dose streptozotocin. J Ethnopharmacol 235:1-7. https://doi.org/10.1016/j.jep.2019.02.001

Ignat I, Volf I, Popa VI (2011) A critical review of methods for characterisation of polyphenolic compounds in fruits and vegetables. Food Chem 126:1821-1835. https://doi.org/10.1016/j.foodchem.2010.12.026

loannou I, Guiga W, Charbonnel C, Ghoul M (2011) Frozen mirabelle plum drying: kinetics, modelling and impact on biochemical properties. Food Bioprod Process 89:438-448. https://doi.org/10.1016/j.fbp.2010.07.001

Jabalbarezi Hukerdi Y, Fathi Nasri MH, Rashidi L, Ganjkhanlou M, Emami A (2019) Effects of dietary olive leaves on performance, carcass traits, meat stability and antioxidant status of fattening Mahabadi male kids. Meat Sci 153:2-8. https://doi.org/10.1016/j.meatsci.2019.03.002

Jasaitis DK, Wohlt JE, Evans JL (1987) Influence of feed ion content on buffering capacity of ruminant Feedstuffs in vitro. J Dairy Sci 70:1391-1403. https://doi.org/10.3168/jds.S0022-0302(87)80161-3

Jung UJ, Lee MK, Jeong KS, Choi MS (2004) The hypoglycemic effects of hesperidin and naringin are partly mediated by hepatic glucose-regulating enzymes in C57BL/KsJ-db/db mice. J Nutr 134:2499-2503. https://doi. org/10.1093/jn/134.10.2499

Kamalak A (2006) Determination of nutritive value of leaves of a native grown shrub, Glycyrrhiza glabra L. using in vitro and in situ measurements. Small Rum Res 64:268-278. https://doi.org/10.1016/j.smallrumres.2005.04.027

Kazemi M (2019) Comparing mineral and chemical compounds, in vitro gas production and fermentation parameters of some range species in Torbat-e Jam. Iran. J Rangel Sci 9:351-363 http://www.rangeland.ir/artic le_663575_b4c0b90111c197e5f3297398c28eddaf.pdf

Kazemi M, Ghasemi Bezdi K (2021) An investigation of the nutritional value of camelthorn (Alhagi maurorum) at three growth stages and its substitution with part of the forage in Afshari ewes' diets. Anim Feed Sci Technol 271:114762. https://doi.org/10.1016/j.anifeedsci.2020.114762

Kazemi M, Valizadeh R (2019) Nutritive value of some rangeland plants compared to medicago sativa. J Rangel Sci 9:136-150. http://www.rangeland. ir/article 544497 05cf90b4d9e8f698ff7feae8899ba8d8.pdf

Kohn RA, Dinneen MM, Russek-Cohen E (2005) Using blood urea nitrogen to predict nitrogen excretion and efficiency of nitrogen utilization in cattle, sheep, goats, horses, pigs, and rats. J Anim Sci 83:879-889. https://doi. org/10.2527/2005.834879x

Komolong MK, Barber DG, McNeill DM (2001) Post-ruminal protein supply and $\mathrm{N}$ retention of weaner sheep fed on a basal diet of lucerne hay (Medicago sativa) with increasing levels of quebracho tannins. Anim Feed Sci Technol 92:59-72. https://doi.org/10.1016/S0377-8401(01)00246-2

Lević J, Prodanović O, Sredanović S (2005) Understanding the buffering capacity in feedstuffs. Biotechnol Anim Husb 21:305-313. https://doi.org/10. 2298/BAH0506309L

Liu F, Ng TB (2000) Antioxidative and free radical scavenging activities of selected medicinal herbs. Life Sci 66:725-735. https://doi.org/10.1016/ S0024-3205(99)00643-8

Liu JX, Yao J, Yan B, Yu JQ, Shi ZQ (2001) Effects of mulberry leaves to replace rapeseed meal on performance of sheep feeding on ammoniated rice straw diet. Small Rum Res 39:131-136. https://doi.org/10.1016/S09214488(00)00180-2 
Liu YN, Jung JH, Park H, Kim H (2014) Olive leaf extract suppresses messenger RNA expression of proinflammatory cytokines and enhances insulin receptor substrate 1 expression in the rats with streptozotocin and highfat diet-induced diabetes. Nutr Res 34:450-457. https://doi.org/10.1016/j. nutres.2014.04.007

Makkar HPS (2003) Effects and fate of tannins in ruminant animals, adaptation to tannins, and strategies to overcome detrimental effects of feeding tannin-rich feeds. Small Rum Res 49:241-256. https://doi.org/ 10.1016/S0921-4488(03)00142-1

Makkar HPS (2003) Quantification of tannins in tree and shrub foliage. a laboratory manual. Kluwer Academic Publishers, Netherlands

Makkar HPS (2010) In vitro screening of feed resources for efficiency of microbial protein synthesis. In: In vitro screening of plant resources for extra-nutritional attributes in ruminants, nuclear and related methodologies. Springer, USA, pp 106-144

Makkar HPS, Blümmel M, Becker K (1995) In vitro effects and interactions of tannins and saponins and fate of tannins in rumen. J Sci Food Agric 69:481-493. https://doi.org/10.1002/jsfa.2740690413

Martens SD, Tiemann TT, Bindelle J, Peters M, Lascano CE (2013) Alternative plant protein sources for pigs and chickens in the tropics - nutritional value and constraints: a review. J Agr Rural Dev Trop 113:101-123. https://jarts.info/index.php/jarts/article/view/2012092441794/191

Menke KH, Steingass H (1988) Estimation of the energetic feed value obtained from chemical analysis and in vitro gas production using rumen fluid. Anim Res Dev 28:7-55

Meschy F (2000) Recent progress in the assessment of mineral requirements of goats. Livest Prod Sci 64:9-14. https://doi.org/10.1016/S03016226(00)00171-8

Min BR, Solaiman S (2018) Comparative aspects of plant tannins on digestive physiology, nutrition and microbial community changes in sheep and goats: a review. J Anim Physiol Anim Nutr 102:1181-1193. https:// doi.org/10.1111/jpn.12938

Moniello G, Infascelli F, Pinna W, Camboni G (2005) Mineral requirements of dairy sheep. Ital J Anim Sci 4:63-74. https://doi.org/10.4081/ijas.2005. $1 \mathrm{s.63}$

Montañez-Valdez OD, Solano-Gama JDJ, Martinez-Tinajero JJ, GuerraMedina CE, Coss ALD, Orozco-Hernandez R (2013) Buffering capacity of common feedstuffs used in ruminant diets. Rev Colomb Cienc Pec 26:37-41. http://www.scielo.org.co/pdf/rccp/v26n1/v26a1a6.pdf

Nowak A, Czyzowska A, Efenberger M, Krala L (2016) Polyphenolic extracts of cherry (Prunus cerasus L.) and blackcurrant (Ribes nigrum L.) leaves as natural preservatives in meat products. Food Microbial 59:142-149. https://doi.org/10.1016/j.fm.2016.06.004

NRC (2007) Nutrient requirements of small ruminants: sheep, goats, cervids, and new world camelids. National Academic Press, Washingto (DC)

Okoruwa MI, Ikhimioya I (2020) Influence of browse-tree leaves supplementation on digestibility, rumen fermentation and performance of goats fed mixed grass hay. LLRD. 32(6). http://www.Irrd.org//rrd32/6/odion 32093.html

Ondiek JO, Tuitoek JK, Abdulrazak SA, Bareeba FB, Fujihara T (2000) Use of Leucaena leucocephala and Gliricidia sepiumas nitrogen sources in supplementary concentrates for dairy goats offered rhodes grass. Asian-Australas J Anim Sci 13:1249-1254. https://doi.org/10.5713/ajas. 2000.1249

Ørskov ER, McDonald I (1979) The estimation of protein degradability in the rumen from incubation measurements weighted according to rate of passage. J Agric Sci 92:499-503. https://doi.org/10.1017/S002185960 0063048

Pal K, Patra AK, SahooA KPK (2015) Evaluation of several tropical tree leaves for methane production potential, degradability and rumen fermentation in vitro. Livest Sci 180:98-105. https://doi.org/10.1016/j.livsci.2015. 07.011

Pambu-Gollah R, Cronjé PB, Casey NH (2000) An evaluation of the use of blood metabolite concentrations as indicators of nutritional status in free-ranging indigenous goats. S Afr J Anim Sci 30:115-120. https://doi. org/10.4314/sajas.v30i2.3859

Patra AK (2009) Responses of intake, digestibility and nitrogen utilization in goats fed low-quality roughages supplemented with tree foliages. J Sci Food Agric 89:1462-1472. https://doi.org/10.1002/jsfa.3610

Pawar MM, Kamra DN, Agarwal N, Chaudhary LC (2014) Effects of essential oils on in vitro methanogenesis and feed fermentation with buffalo rumen liquor. Agric Res 3:67-74. https://doi.org/10.1007/ s40003-014-0092-Z

Placer ZA, Cushman LL, Johnson BC (1966) Estimation of product of lipid peroxidation (malonyl dialdehyde) in biochemical systems. Anal Biochem 16:359-364. https://doi.org/10.1016/0003-2697(66)90167-9

Raghuvansi SKS, Prasad R, Mishra AS, Chaturvedi OH, Tripathi MK, Misra AK, Saraswat BL, Jakhmola RC (2007) Effect of inclusion of tree leaves in feed on nutrient utilization and rumen fermentation in sheep. Bioresour Technol 98:511-517. https://doi.org/10.1016/j.biortech.2006. 02.008

Reig G, Front i Forcada C, Mestre L, Jiménez S, Betrán JA, Moreno MÁ (2018) Horticultural, leaf mineral and fruit quality traits of two 'Greengage' plum cultivars budded on plum based rootstocks in Mediterranean conditions. Sci Hortic 232:84-91. https://doi.org/10.1016/j.scienta.2017. 12.052

Ribeiro DM, Mourato MP, Almeida AM (2019) Assessing mineral status in edible tissues of domestic and game animals: a review with a special emphasis in tropical regions. Trop Anim Health Prod 51:1019-1032. https://doi.org/10.1007/s11250-019-01848-8

Rubanza CDK, Shem MN, Otsyina R, Ichinohe T, Fujihara T (2003) Nutritive evaluation of some browse tree legume foliages native to semi-arid areas in Western Tanzania. Asian-Australas J Anim Sci 16:1429-1437. https://doi.org/10.5713/ajas.2003.1429

Salem AZM (2005) Impact of season of harvest on in vitro gas production and dry matter degradability of Acacia saligna leaves with inoculum from three ruminant species. Anim Feed Sci Technol 123-124:67-79. https://doi.org/10.1016/j.anifeedsci.2005.04.042

Salem HB, Makkar HPS, Nefzaoui A, Hassayoun L, Abidi S (2005) Benefit from the association of small amounts of tannin-rich shrub foliage (Acacia cyanophylla Lindl.) with soya bean meal given as supplements to Barbarine sheep fed on oaten hay. Anim Feed Sci Technol 122:173-186. https://doi.org/10.1016/j.anifeedsci.2005.04.012

Salem AZM, Salem MZM, El-Adawy MM, Robinson PH (2006) Nutritive evaluations of some browse tree foliages during the dry season: secondary compounds, feed intake and in vivo digestibility in sheep and goats. Anim Feed Sci Technol 127:251-267. https://doi.org/10.1016/j.anife edsci.2005.09.005

Salem AZM, Robinson PH, El-Adawy MM, Hassan AA (2007) In vitro fermentation and microbial protein synthesis of some browse tree leaves with or without addition of polyethylene glycol. Anim Feed Sci Technol 138:318-330. https://doi.org/10.1016/j.anifeedsci.2006.11.026

SAS (2002) Statistical analysis system. User's Guide: Statistics. SAS Institute, Cary, NC, USA

Shakeri P, Durmic Z, Vadhanabhuti J, Vercoe PE (2017) Products derived from olive leaves and fruits can alter in vitro ruminal fermentation and methane production. J Sci Food Agric 97:1367-1372. https://doi.org/ 10.1002/jsfa.7876

Silanikove N, Perevolotsky A, Provenza FD (2001) Use of tannin binding chemicals to assay for tannins and their negative post-ingestive effects in ruminants. Anim Feed Sci Technol 91:69-81. https://doi.org/10.1016/ S0377-8401(01)00234-6

Sniffen CJ, O'Conno JD, Van Soest PJ, Fox DG, Russell JB (1992) A net carbohydrate and protein system for evaluating cattle diets. II. Carbohydrate and protein availability. J Anim Sci 70:3562-3577. https://doi.org/10. 2527/1992.70113562x

Stacewicz-Sapuntzakis M, Bowen PE, Hussain EA, Damayanti-Wood BI, Farnsworth NR (2001) Chemical composition and potential health effects of prunes: a functional food? Crit Rev Food Sci Nutr 41:251-286. https:// doi.org/10.1080/20014091091814

Topps JH (1992) Potential, composition and use of legume shrubs and trees as fodder for livestock in the tropics (a review). J Agric Sci 118:1-8. https://doi.org/10.1017/S0021859600067940

Umar A, Iskandar G, Aikemu A, Yiming W, Zhou W, Berké B, Begaud B, Moore N (2015) Effects of Cydonia oblonga Miller leaf and fruit flavonoids on blood lipids and anti-oxydant potential in hyperlipidemia rats. J Ethnopharmacol 169:239-243. https://doi.org/10.1016/j.jep.2015.04.038

Van Soest PJ, Robertson JB, Lewis BA (1991) Methods for dietary fiber, neutral detergent fiber, and non-starch polysaccharides in relation to animal nutrition. J Dairy Sci 74:3583-3597. https://doi.org/10.3168/jds. S0022-0302(91)78551-2 
Xie C, Xie Z, Xu X, Yang D (2015) Persimmon (Diospyros kaki L.) leaves: a review on traditional uses, phytochemistry and pharmacological properties. J Ethnopharmacol 163:229-240. https://doi.org/10.1016/j. jep.2015.01.007

Zhang K, Zhang Y, Zhang M, Gu L, Liu Z, Jia J, Chen X (2016) Effects of phospholipid complexes of total flavonoids from Persimmon (Diospyros kaki L.) leaves on experimental atherosclerosis rats. J Ethnopharmacol 191:245-253. https://doi.org/10.1016/j.jep.2016.06.043

\section{Publisher's Note}

Springer Nature remains neutral with regard to jurisdictional claims in published maps and institutional affiliations.

\section{Submit your manuscript to a SpringerOpen ${ }^{0}$ journal and benefit from:}

- Convenient online submission

- Rigorous peer review

- Open access: articles freely available online

- High visibility within the field

- Retaining the copyright to your article

Submit your next manuscript at $\boldsymbol{\nabla}$ springeropen.com 